\title{
The Effect of PPAR Agonists on the Migration of Mature and Immature Eosinophils
}

\author{
Steven G. Smith, ${ }^{1}$ Haruki Imaoka, ${ }^{2}$ Neha Punia, ${ }^{1}$ Anam Irshad, \\ Luke L. Janssen, ${ }^{1}$ Roma Sehmi, ${ }^{1}$ and Gail M. Gauvreau ${ }^{1}$ \\ ${ }^{1}$ Department of Medicine, McMaster University, Hamilton, ON, Canada L8S 4K1 \\ ${ }^{2}$ Department of Medicine, Kurume University School of Medicine, Kurume, Fukuoka 830-0011, Japan
}

Correspondence should be addressed to Gail M. Gauvreau, gauvreau@mcmaster.ca

Received 29 February 2012; Accepted 7 May 2012

Academic Editor: Raju Reddy

Copyright (C) 2012 Steven G. Smith et al. This is an open access article distributed under the Creative Commons Attribution License, which permits unrestricted use, distribution, and reproduction in any medium, provided the original work is properly cited.

\begin{abstract}
PPAR $y$ agonists can either enhance or inhibit eosinophil migration, which is a sum of directional migration (chemotaxis) and random cell movement (chemokinesis). To date, the effects of PPAR agonists on chemokinesis have not been examined. This study investigates the effects of $\operatorname{PPAR} \alpha, \delta$, and $\gamma$ agonists on eosinophil migration and chemokinesis. Eosinophils purified from blood of atopic donors were preincubated with rosiglitazone (PPAR $\gamma$ agonist), GW9578 (PPAR $\alpha$ agonist), GW501516 (PPAR $\delta$ agonist), or diluent. The effects of PPAR agonists were examined on eosinophil chemokinesis, eotaxin-induced migration of eosinophils, and migration of IL-5R $\alpha+$ CD34+ cells. Expressions of CCR3, phospho-p38, phospho-ERK, and calcium release were also measured in eosinophils after rosiglitazone treatment. Low concentrations of rosiglitazone, but not GW9578 or GW501516, increased chemokinesis of eosinophils $(P=0.0038)$, and SDF- $1 \alpha$-induced migration of immature eosinophils $(P=0.0538)$. Rosiglitazone had an effect on eosinophil calcium flux but had no effect on expression of CCR3 or phosphorylation of p38 or ERK. In contrast, high concentrations of rosiglitazone inhibited eosinophil migration $(P=0.0042)$. The effect of rosiglitazone on eosinophil migration and chemokinesis appears to be through modification of calcium signaling, which alludes to a novel PPAR-mediated mechanism to modulate eosinophil function.
\end{abstract}

\section{Introduction}

Eosinophils are effector cells which contribute to the pathology of allergic diseases [1]. They are recruited from the blood into inflamed tissue by local release of chemokines $[2,3]$. Eotaxin-1, which is one of the most potent eosinophil chemokines, signals through chemokine receptor 3 (CCR3). Novel approaches toward inhibiting migration of effector cells such as eosinophils are being investigated for treatment of allergic asthma.

The peroxisome proliferator-activated receptors (PPARs) are metabolite-activated transcription factors that have been shown to regulate metabolic and inflammatory responses [4]. There are three identified subtypes of PPARs: PPAR $\alpha$ [5], PPAR $\gamma$ [6], and PPAR $\delta$ [7], which have attracted interest as therapeutic targets in lung disease due to their preferential expression on human airway smooth muscle [8] and inflammatory cells [9] and increased expression during inflammatory events $[10,11]$. In murine models of allergic asthma, PPAR $\alpha$ and PPAR $\gamma$ agonists (rosiglitazone and GW9578, resp.) inhibit eosinophil influx to the lung following airway antigen challenge $[12,13]$. The PPAR $y$ agonist was more effective than the PPAR $\alpha$ agonist, while the $\operatorname{PPAR} \delta$ agonist had no effect [13].

At low concentrations, however, PPAR agonists have been shown to enhance eosinophil migration in vitro [14]. The observed enhancement in eosinophil migration could be due to an increase in chemotaxis or chemokinesis [15], and the current study will compare the effects of low concentrations of the PPAR agonists GW9578, GW501516, and rosiglitazone on eosinophil migration and chemokinesis.

\section{Materials and Methods}

2.1. Subjects. Blood was obtained from 10 male and 13 female, nonsmoking, atopic donors aged 19-60 years old. 
Atopy was confirmed by skin prick testing. Subjects were not currently using steroidal or nonsteroidal anti-inflammatory medications or antihistamines. Samples of cord blood were obtained from the hospital delivery room from 6 individuals whose atopic status and medication use were not determined. The study was approved by the FHS/HHS Research Ethics Board, and subjects gave informed consent to participate.

2.2. Eosinophil Purification. One hundred $\mathrm{mL}$ of peripheral blood was collected from each subject into sodium heparin vacutainers for in vitro experiments. Peripheral blood was diluted with an equal volume of McCoy's 5A (Invitrogen Canada Inc., Burlington, ON, Canada), and eosinophils were purified using an AccuPrep density gradient (Accurate Chemical \& Scientific Corporation, Westbury, NY, USA) followed by a MACS column CD16+ neutrophil depletion (Miltenyi Biotec, Auburn, CA, USA). The purity of each eosinophil sample was determined with a CytoPrep stained for a cell differential count (Diff Quik; Siemens Healthcare Diagnostics, Deerfield, IL, USA). Light microscopy demonstrated that the eosinophil preparations were $>90 \%$ pure and the majority of contaminating cells were neutrophils.

Purified eosinophils were resuspended in RPMI complete (10\% Fetal Bovine Serum, 1 M HEPES in RPMI 1640) and incubated for 20 minutes with $0.1 \mathrm{nM}-100 \mu \mathrm{M}$ of either a PPAR $\alpha$ agonist (GW9578; Cayman Chemical, Ann Arbor, MI, USA), a PPAR $\beta / \delta$ agonist (GW501516; Axxora LLC, San Diego, CA, USA), or a PPAR $\gamma$ agonist (rosiglitazone; Cayman Chemical, Ann Arbor, MI, USA), all in a final concentration of $0.1 \%$ DMSO, or with diluent (RPMI complete in $0.1 \%$ DMSO). Treatment with PPAR agonists had no effect on eosinophil viability as determined by trypan blue exclusion, being $>98 \%$ viable before and after incubation.

2.3. Eotaxin-Induced Eosinophil Migration. The migration assay used a 48-well Boyden chamber, following protocols from previous studies on eosinophil migration [16]. The PPAR agonists were left in the cell suspension, and the upper wells of the Boyden chamber were filled with $50 \mu \mathrm{L}$ of eosinophils at a concentration of $3 \times 10^{6}$ cells $/ \mathrm{mL}$. Eotaxin at a concentration of $10 \mathrm{nM}$ (R\&D Systems, Minneapolis, MN, USA) in the presence of equivalent concentrations of PPAR agonist $(0.1 \mathrm{nM}-100 \mu \mathrm{M})$ was placed in the lower wells of the microchemotaxis assembly (Neuro Probe Inc., Gaithersburg, MD, USA). The upper and lower wells were separated by a nitrocellulose filter with an $8 \mu \mathrm{m}$ pore, and the chamber was incubated in high humidity for 90 minutes at $37^{\circ} \mathrm{C}$. The chamber was then disassembled, and the nitrocellulose filter was fixed with mercuric chloride overnight and stained with hematoxylin and chromotrope 2R. The filter were dehydrated through graded alcohols followed by a 30minute xylene treatment, then mounted on a glass slide and coverslipped with Permount (Fisher Scientific, Pittsburgh, PA, USA). The number of eosinophils was quantified from 10 random fields at the leading edge, counted from the underside of the filter using a light microscope at 400x magnification.
2.4. PPAR Agonist-Induced Eosinophil Chemokinesis. To determine the effects of PPARs on eosinophil chemokinetic responses, eosinophils were incubated with PPAR agonists $(0.1 \mathrm{nM}-100 \mu \mathrm{M})$ for 20 minutes then loaded into the upper chamber with similar concentrations of the PPAR agonist in the lower chambers.

2.5. Eosinophil CCR3 Expression. Purified eosinophils were incubated with rosiglitazone at $0.1 \mathrm{nM}$ or $10 \mathrm{nM}$ or diluent for 110 minutes. The cells were then stained for CCR3 surface expression using mouse anti-human Pacific BlueCD45 (eBioscience, San Diego, CA, USA), FITC-CD16 (Becton-Dickinson Biosciences, Mississauga, ON, Canada), and PE-CCR3 (Medical \& Biological Laboratories, Naka$\mathrm{ku}$, Nagoya, Japan), as well as the isotype control antibodies for CCR3. Cells were acquired with an LSR II flow cytometer (Becton Dickinson Instrument Systems; BectonDickinson, Mississauga, ON, Canada) using the FACSDiva software program (Becton-Dickinson Biosciences). Fluorometric compensation was set to minimize autofluorescence, a known issue surrounding eosinophil and flow cytometry [17].

\subsection{Eosinophil Migration-Signal Transduction Pathways.} Purified eosinophils were treated with rosiglitazone at concentrations which was previously reported to induce cell migration $(0.1 \mathrm{nM}, 10 \mathrm{nM})$ [14] or with diluent for 110 minutes in the absence or presence of $10 \mathrm{nM}$ eotaxin. After rosiglitazone treatment, eosinophils were lysed and the protein concentration was standardized using a Bradford assay. Phosphorylation of ERK1/2 and p38 was analyzed using signal transduction assay reaction (STAR) ELISA kits (Millipore, Temecula, CA, USA) and quantified by measuring the absorbance at $450 \mathrm{~nm}$ using an EL800 plate reader (BioTek Instruments, Winooski, VT, USA).

2.7. Eosinophil Progenitor Cell Transwell Migration. Cord blood was diluted with an equal volume of McCoy's 5A (Invitrogen Canada Inc.), and mononuclear cells were purified using an AccuPrep density gradient (Accurate Chemical \& Scientific Corporation, Westbury, NY, USA). Non-adherent mononuclear cells (NAMCs) were then resuspended in McCoy's 3+ (McCoy's 5A with 10\% fetal bovine serum, $1 \%$ penicillin/streptomycin, and $1 \% 2$ mercaptoethanol) and incubated for 2 hours in $5 \% \mathrm{CO}_{2}$ at $37^{\circ} \mathrm{C}$ and high humidity to remove monocytes. CD34+ progenitor cells were isolated using a MACS column CD34+ positive selection (Miltenyi Biotec, Auburn, CA, USA). The $\mathrm{CD} 34+$ progenitor cell preparations were $>90 \%$ viable after isolation.

CD34+ progenitor cells were resuspend at $1 \times 10^{6}$ cells $/ \mathrm{mL}$ in RPMI complete $(10 \%$ fetal bovine serum, $1 \mathrm{M}$ HEPES in RPMI 1640) with $100-1000 \mathrm{nM}$ of PPAR $\alpha$ agonist (GW9578), PPAR $\beta / \delta$ agonist (GW501516), or PPAR $\gamma$ agonist (rosiglitazone) agonist, all in a final concentration of $0.1 \%$ DMSO or diluent (RPMI complete in $0.1 \%$ DMSO). SDF- $1 \alpha$ (R\&D Systems) at a concentration of $100 \mathrm{ng} / \mathrm{mL}$ in the presence of equivalent concentrations of PPAR agonists 
$(100-1000 \mathrm{nM})$ was placed in the lower wells of the transwell assembly. The chamber was incubated in high humidity for 18 hours at $37^{\circ} \mathrm{C}$. The chamber was then disassembled, and the cells from the lower well were stained for CD34 and IL-5R $\alpha$ surface expression using mouse anti-human CD34-APC, CD45-FITC, and PE-IL-5R $\alpha$ (Becton-Dickinson Biosciences), as well as the isotype control antibodies for CCR3. Cells were acquired with an LSR II flow cytometer (Becton Dickinson Instrument Systems; Becton-Dickinson) using the FACSDiva software program (Becton-Dickinson Biosciences). Migration was expressed as \% of total CD34+ cells plated.

2.8. Image Acquisition and Measurement of $\left[\mathrm{Ca}^{2+}\right]_{i}$. Intracellular changes in calcium were measured using confocal microscopy, as previously described [18]. Briefly, isolated eosinophils $\left(1 \times 10^{6}\right.$ cells $\left./ \mathrm{mL}\right)$ were loaded for $1 \mathrm{hr}$ on ice with $3.5 \mu \mathrm{M}$ of a $\mathrm{Ca}^{2+}$-sensitive fluorescent probe, fluo-3 AM (Invitrogen Canada) dissolved in dimethyl sulfoxide with $0.01 \%$ Pluronic F-127. The eosinophils were then loaded onto a culture dish and placed on the stage of a custom-built confocal microscope equipped with a 20x objective. The bathing solution for all experiments was RPMI, maintained at $37^{\circ} \mathrm{C}$, which was exchanged constantly via superfusion throughout the experiment. Eosinophils were then illuminated using $488 \mathrm{~nm}$ light from a $20 \mathrm{~mW}$ photodiode laser (Coherent Technologies; CA, USA). During the recordings eosinophils were exposed to control (diluent or eotaxin) or treatment (diluent with $100 \mathrm{nM}$ rosiglitazone or eotaxin with $100 \mathrm{nM}$ rosiglitazone). Images $(480 \times 640$ pixels) were collected at $30 \mathrm{~Hz}$ with the imaging software "Video Savant" (IO Industries; London, ON, Canada); 9 consecutive frames were then averaged at 1.5 second intervals, giving a final image rate of $0.67 \mathrm{~Hz}$. The image analysis software, "Scion" (Scion Corporation, Frederick, $\mathrm{MD}$, USA), was used to determine the pixel intensity of 10 individual cells for measurement of $\left[\mathrm{Ca}^{2+}\right]_{i}$. Fluorescence intensities of the regions of interest were saved and plotted against time. An increase in average fluorescence intensity was interpreted as an increase in $\left[\mathrm{Ca}^{2+}\right]_{i}$, and an increase in the average frequency of $\left[\mathrm{Ca}^{2+}\right]_{i}$ spikes was interpreted as an increase in $\left[\mathrm{Ca}^{2+}\right]_{i}$ oscillations.

2.9. Statistical Analysis. All data are expressed as the mean \pm standard error unless otherwise stated. Statistical analyses were performed using Prism version 5 (GraphPad Software, La Jolla, CA, USA). Analysis of variance (ANOVA) was used to compare PPAR agonist treatments versus diluent at the various doses, with post hoc Tukey tests for prespecified comparisons. For data not normally distributed, the statistics were performed on the log-transformed data. Statistically significant differences were accepted at $P<0.05$.

\section{Results and Discussion}

3.1. Subjects. Blood donors that were recruited for the study were $31 \pm 12$ years old with mild blood eosinophilia $(3.9 \pm 2 \%$ eosinophils).
3.2. Effects of PPAR Agonists on Eotaxin-Induced Eosinophil Migration. The chemokine eotaxin $(10 \mathrm{nM})$ induced significant eosinophil migration compared to diluent control $(242.9 \pm 148.6$ versus $46.1 \pm 68.1$ cells $/ 10 \mathrm{HPF}, P<0.0001)$. PPAR agonists were tested at low concentrations $(n=9$, Figures $1(\mathrm{a}), 1(\mathrm{~b})$, and $1(\mathrm{c}))$ and high concentrations $(n=6$, Figures 1(a), 1(b), and $1(\mathrm{c}))$. Preincubation with $100 \mu \mathrm{M}$ rosiglitazone significantly inhibited eosinophil migration (Figures $1(\mathrm{a})$ and $1(\mathrm{e}) ; P=0.0042)$. By contrast, there was no effect of GW9578 $(P=0.9)$ or GW501516 $(P=0.3)$ on eotaxin-induced migration (Figures $1(\mathrm{~b})$ and $1(\mathrm{c})$ ).

Rosiglitazone treatment alone at a concentration of $100 \mathrm{nM}$ both above and below the nitrocellulose filter in the micro-Boyden chamber assay significantly increased the eosinophil chemokinesis compared to diluent control $(P=$ 0.0038; Figures 2(a) and 2(e)). In contrast, no chemokinetic responses were observed when eosinophils were incubated with equivalent concentrations of GW9578 (PPAR $\alpha$ agonist, $P=0.9$ ) or GW501516 (PPAR $\delta$ agonist, $P=0.9$ ) above and below the filter (Figures 2(b) and 2(c)), or with a high concentration of rosiglitazone (Figure $2(\mathrm{a}), P=0.05$ ).

Cell migration is a multistep process, which involves both chemotaxis and chemokinesis in response to a chemokine [19]. Chemotaxis is defined as directed migration towards a chemokine, whereas chemokinesis is defined as nondirectional migration. Chemokinesis, alone, is not sufficient for cell accumulation but may contribute considerably by priming a cell to respond more vigorously to a chemotactic stimuli [20]. Previously it was unknown whether the increase in eotaxin-induced migration by $\operatorname{PAAR} \gamma$ agonists was due to chemotaxis, chemokinesis, or both. Although PPAR agonists in this in vitro study are used at concentrations similar to the reported $\mathrm{EC}_{50}$ s those for rosiglitazone, GW9578, and GW501516 are $43 \mathrm{nM}, 50 \mathrm{nM}$, and $1.1 \mathrm{nM}$, respectively [2123], this study has determined that the enhanced migration by rosiglitazone is likely due to a chemokinetic effect. Such "priming" of cells may enhance their response to other stimuli, including chemokines such as eotaxin that are found in the microenvironment of allergic tissue, and thus lead to eosinophilia.

3.3. Effect of Rosiglitazone on Eosinophil CCR3 Surface Expression and Signaling. Incubation with rosiglitazone at 0.1 and $10 \mathrm{nM}$ had no effect on eosinophil CCR3 surface expression (Table 1). Furthermore, eosinophil incubation with rosiglitazone in the presence or absence of eotaxin had no effect on the level of phosphorylation of ERK1/2 or p38 MAPK (Table 1).

To improve our understanding of how PPAR agonists regulate eotaxin-induced eosinophil migration, we investigated the effects of rosiglitazone on the surface expression and downstream signalling of the eotaxin receptor, CCR3. Consistent with studies of other PPAR $y$ agonists, 15d$\mathrm{PGJ}_{2}$ and troglitazone [14], which were studied at similar concentrations, we observed no effect of rosiglitazone on the level of cell surface expression of CCR3 on eosinophils or on phosphorylation of the downstream signaling molecules ERK1/2 and $\mathrm{p} 38$. 


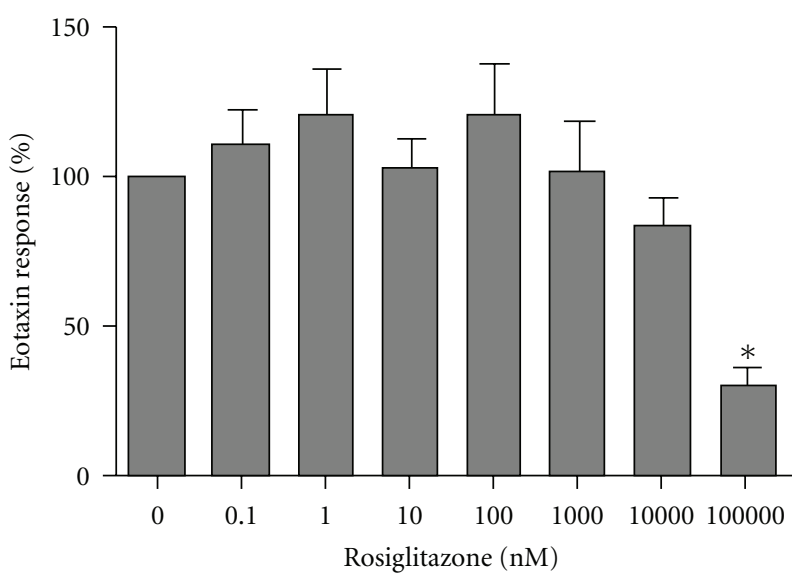

(a)

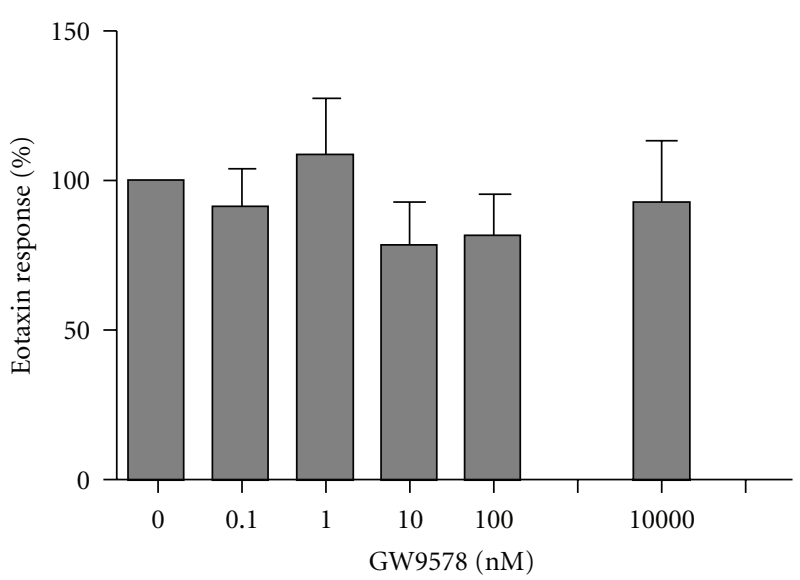

(b)

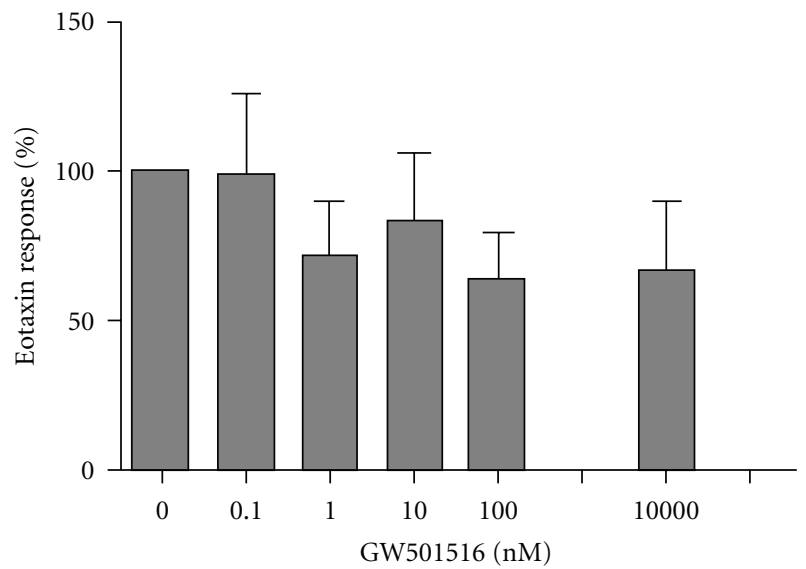

(c)

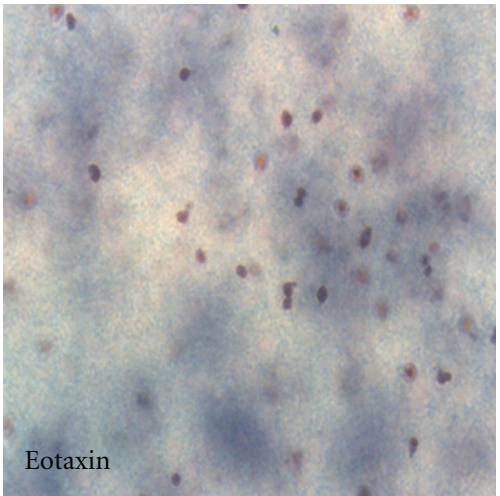

(d)

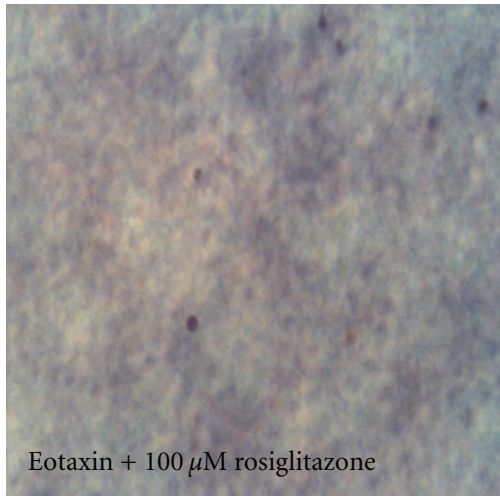

(e)

FIGURE 1: The effect on eotaxin-induced eosinophil migration of agonists to PPAR $\gamma$ ((a) rosiglitazone), PPAR $\alpha$ ((b) GW9578), and PPAR $\delta$ ((c) GW50516) at low (0.1-100 nM; 9 subjects) and high concentrations (1000-100,000 nM; 6 subjects). Representative pictures at 200x magnification of the leading edge of the nitrocellulose filter after incubation with eotaxin (d) and eotaxin with $100 \mu \mathrm{M}$ rosiglitazone (e). Data are shown as mean \pm SEM and expressed as $\%$ of the response to eotaxin.

3.4. Effects of PPAR Agonist on SDF-1 $\alpha$-Induced Eosinophil Progenitor Cell Migration. Compared to diluent control, stromal cell-derived factor- $1 \alpha(100 \mathrm{ng} / \mathrm{mL})$ induced migration of IL-5R $\alpha+$ CD34+ cells isolated from cord blood $(8.2 \pm 6.2$ versus $33.2 \pm 6.1 \%$ of total cells migrated,
$P=0.0479$ ). Low concentrations of rosiglitazone increased the migrational response of cord blood-derived IL-5R $\alpha+$ CD34 cells to SDF- $1 \alpha$ compared to diluent control; however, this change did not reach the level of statistical significance (Figure 3; $P=0.054$ ). No changes in migration of IL-5R $\alpha+$ 


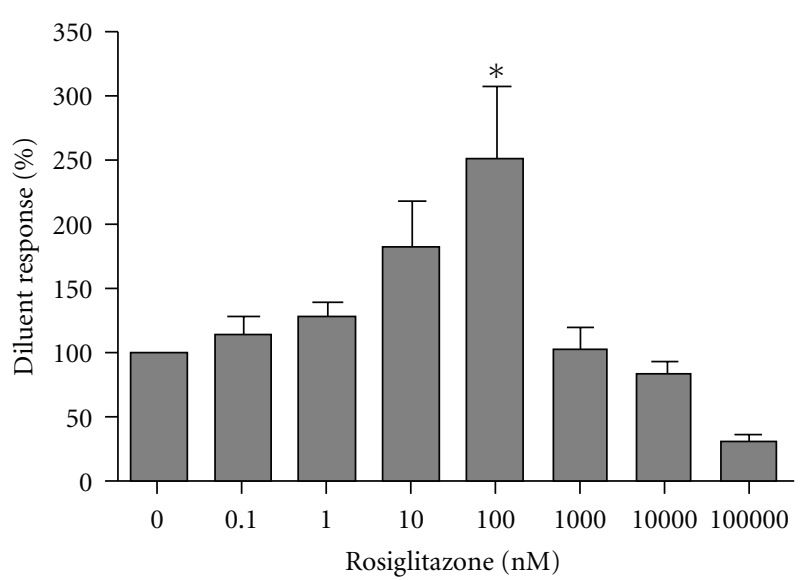

(a)

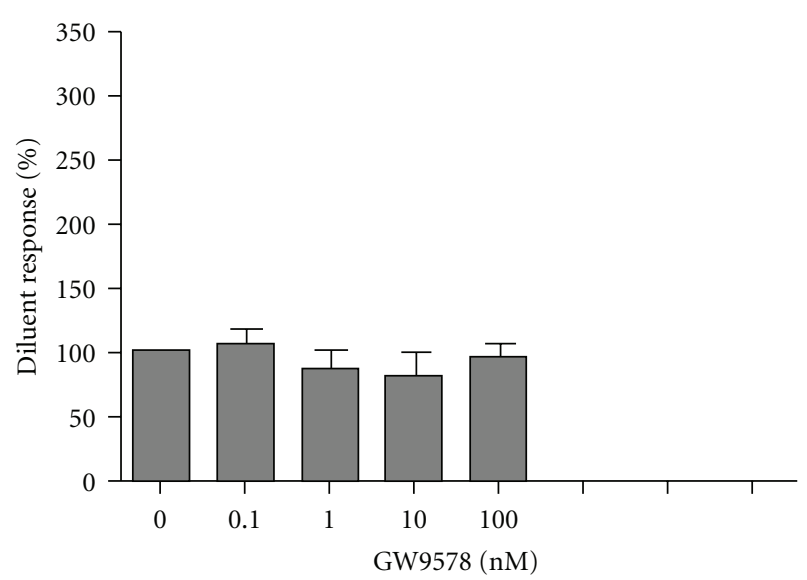

(b)

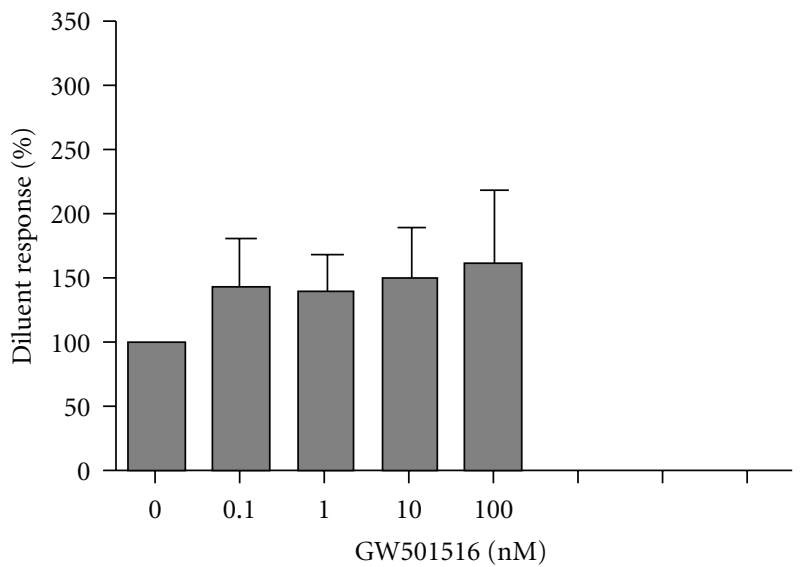

(c)

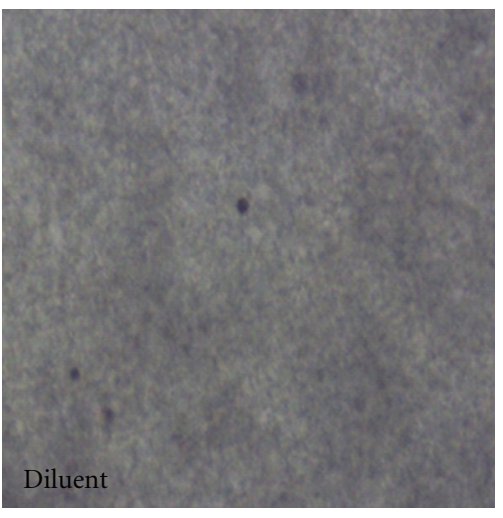

(d)

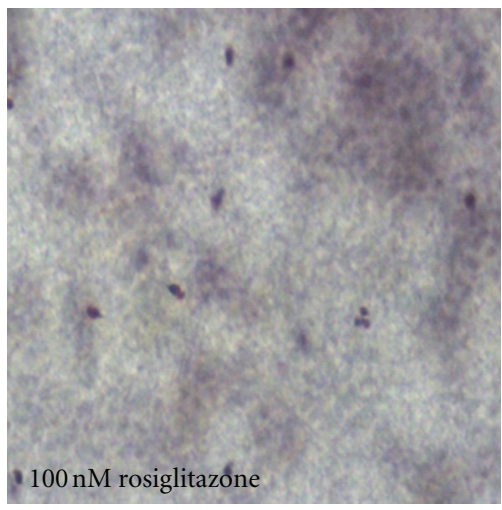

(e)

FIGURE 2: The effect on eosinophil chemokinesis of agonists to PPAR $\gamma((\mathrm{a})$ rosiglitazone), PPAR $\alpha$ ((b) GW9578), and PPAR $\delta$ ((c) GW50516) at low (0.1-100 nM; 9 subjects) and for PPAR $\gamma$ (a; rosiglitazone) at high concentrations (1000-100,000 nM; 6 subjects). Representative pictures at 200x magnification of the leading edge of the nitrocellulose filter after incubation with diluent (d) and $100 \mathrm{nM}$ rosiglitazone (e). Data are shown as mean \pm SEM and expressed as \% of the response to diluent.

CD34+ cells were observed with equivalent concentrations of GW9578 (PPAR $\alpha$ agonist, $P=0.8$ ) or GW501516 (PPAR $\delta$ agonist, $P=0.6$ ) (data not shown).

We also examined the effect of PPAR agonists on the immature eosinophil population of IL-5R $\alpha+$ CD34 cells purified from cord blood samples. We demonstrated that migration of these immature eosinophils in response to the potent chemoattractant SDF- $1 \alpha$ is likewise enhanced by pretreatment of low concentrations of rosiglitazone. This finding is novel and mirrors our and Koybayashi's [14] 
TABLE 1: Eosinophil expression of CCR3 and phosphorylation of ERK1/2 and p38 after treatment with the PPAR $\gamma$ agonist rosiglitazone.

\begin{tabular}{|c|c|c|c|c|c|}
\hline & & Diluent & $0.1 \mathrm{nM}$ & $10 \mathrm{nM}$ & $P$ value \\
\hline CCR3 (\%) & & $29.3 \pm 7.5$ & $23.5 \pm 5.7$ & $19.8 \pm 4.7$ & 0.1 \\
\hline CCR3 (MFI) & & $8.3 \pm 4.4$ & $6.8 \pm 3.3$ & $5.4 \pm 2.8$ & 0.2 \\
\hline \multirow{2}{*}{ Phospho-ERK1/2 (units/mL) } & Diluent & $3.5 \pm 0.7$ & $3.3 \pm 0.6$ & $3.3 \pm 0.5$ & 0.6 \\
\hline & Eotaxin & $3.75 \pm 0.2$ & $3.93 \pm 0.4$ & $3.95 \pm 0.4$ & 0.8 \\
\hline \multirow{2}{*}{ Phospho-p38 (units/mL) } & Diluent & $3.9 \pm 1$ & $4.8 \pm 1.3$ & $4.5 \pm 1.8$ & 0.9 \\
\hline & Eotaxin & $6.7 \pm 1.9$ & $6.2 \pm 1.5$ & $7.0 \pm 1.4$ & 0.8 \\
\hline
\end{tabular}

Data represent mean \pm SEM.

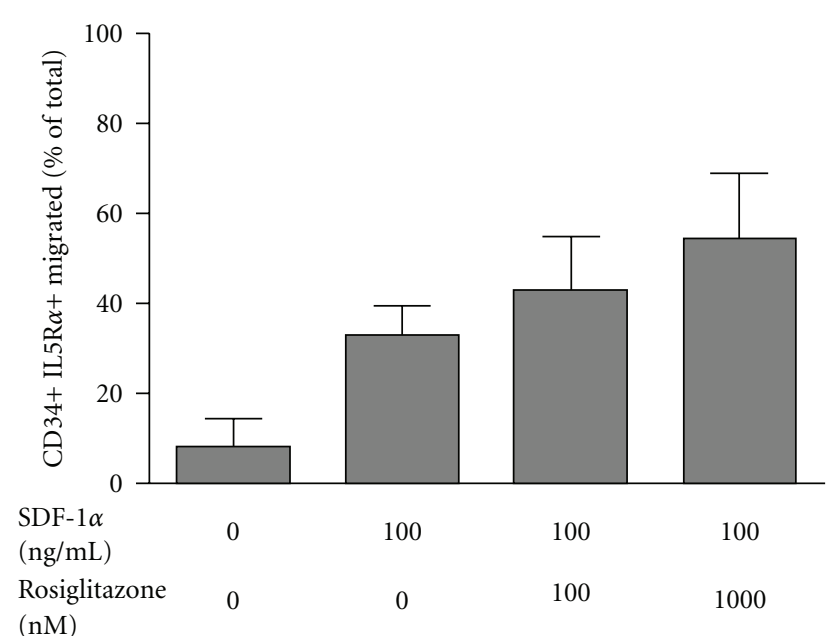

Figure 3: The effect of the PPAR $\gamma$ agonist rosiglitazone on SDF$1 \alpha$-induced migration of IL-5R $\alpha+$ CD $34+$ cells isolated from cord blood (6 subjects). Data are shown as mean \pm SEM and expressed as a $\%$ of the total IL- $5 \mathrm{R} \alpha+\mathrm{CD} 34+$ cells.

observations in mature eosinophils, of enhanced migration by low concentrations of PPAR $\gamma$ agonist, with no effect of $\operatorname{PPAR} \alpha$ and $\delta$ agonists.

3.5. Image Acquisition and Measurement of $\left[\mathrm{Ca}^{2+}\right]_{i}$. Calcium flux was examined in 3 separate eosinophil preparations. Addition of eotaxin to eosinophil preparations caused an increase in maximum fluorescence intensity (Figure 4; diluent $16.6 \pm 6.2$ versus eotaxin $66.7 \pm 27.4)$ and the number of calcium oscillations (diluent $0.007 \pm 0.004 \mathrm{~Hz}$ versus eotaxin $0.038 \pm 0.016 \mathrm{~Hz}$ ). Treatment with $100 \mathrm{nM}$ rosiglitazone consistently reduced the frequency of calcium oscillations observed after the addition of $10 \mathrm{nM}$ eotaxin (control $0.038 \pm 0.016 \mathrm{~Hz}$ versus treatment $0.016 \pm 0.007 \mathrm{~Hz}$ ). However, no consistent effect of rosiglitazone was observed on the maximum fluorescence intensity in the 3 preparations studied (control $66.7 \pm 27.4$ versus treatment $58.1 \pm 25.2$ ).

Previous studies have shown that pretreatment with a MEK inhibitor or a p38 MAPK inhibitor had no effect on enhanced migration nor did inhibition of the NF- $\kappa$ B pathway or inhibition of genomic transcription with actinomycin D [14]. We and others have shown that PPAR agonists have

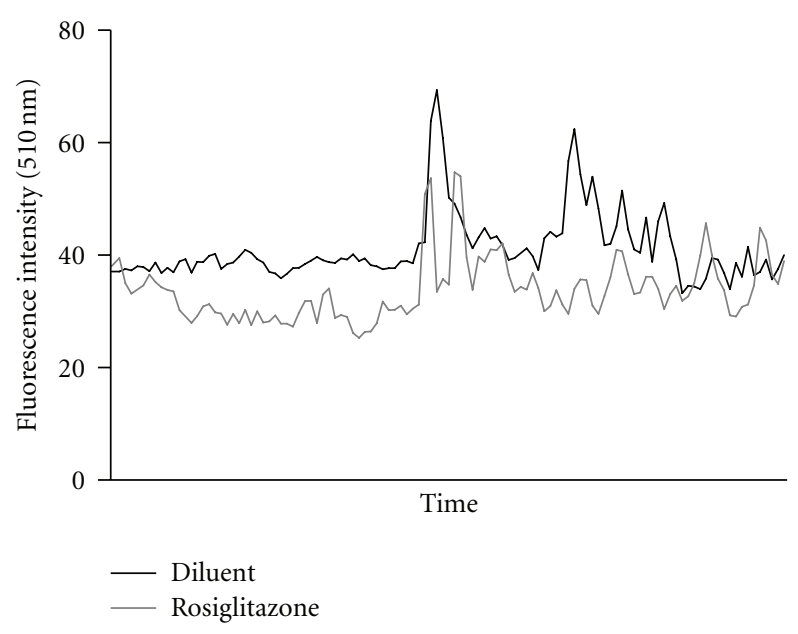

FIGURE 4: The effect of $100 \mathrm{nM}$ rosiglitazone treatment on the eotaxin-induced increase in $\left[\mathrm{Ca}^{2+}\right]_{i}$, measured by the frequency of calcium oscillations and maximum fluorescence intensity (representative tracing from 3 experiments).

a modulatory effect on eotaxin-induced calcium mobilization [14], which would suggest that PPAR agonists have downstream targets which have not been identified yet.

\section{Conclusion}

This is the first study to show increased chemokinesis of eosinophils in vitro at low concentrations of rosiglitazone, which has a 100-fold higher binding affinity for PPAR $y$ than troglitazone [24]. The results of this study also confirm previous observations showing that high concentrations of a PPAR $\gamma$ agonist inhibit eosinophil migration [24].

We demonstrated that the PPAR $y$ agonist rosiglitazone, at a concentration of $100 \mathrm{nM}$ significantly increased eotaxininduced eosinophil chemokinesis in vitro. This finding supports the data demonstrating increased eosinophil migration reported by Kobayashi et al. [14]. We also demonstrated that rosiglitazone treatment had no effect on the level of cell surface expression of the eotaxin receptor, CCR3, on eosinophils, or on the downstream signalling events following eotaxin/CCR3 binding, such as phosphorylation of ERK1/2 and p38 MAPK, suggesting that the observed effects 
of rosiglitazone are not related to alterations in signalling through the eotaxin receptor. At these same concentrations there was no effect of the PPAR $\alpha$ agonist, GW9578, or the $\operatorname{PPAR} \delta$ agonist, GW501516.

In summary, at low concentrations the PPAR $\gamma$ agonist rosiglitazone enhanced chemokinesis of eosinophils isolated from the peripheral blood of atopic subjects and also enhanced the migration of eosinophil progenitors. This chemokinetic effect may at least partially explain the enhancement of eosinophil migration seen at these concentrations. The enhanced chemokinesis was specific for the PPAR $\gamma$ agonist, as there was no effect of $\operatorname{PPAR} \alpha$ or $\operatorname{PPAR} \delta$ agonists. In light of our findings that a selective $\operatorname{PPAR} \gamma$ agonist can enhance eosinophil chemokinesis at a concentration of $100 \mathrm{nM}$ and decrease eosinophil migration at a concentration of $100 \mu \mathrm{M}$, the therapeutic window for $\operatorname{PPAR} \gamma$ agonists as an anti-inflammatory therapy is narrow and dosage must be titrated carefully.

\section{Acknowledgments}

This study was funded by an Ontario Thoracic Society Block Term Seed Grant.

\section{References}

[1] S. P. Hogan, H. F. Rosenberg, R. Moqbel et al., "Eosinophils: biological properties and role in health and disease," Clinical and Experimental Allergy, vol. 38, no. 5, pp. 709-750, 2008.

[2] S. Okada, H. Kita, T. J. George, G. J. Gleich, and K. M. Leiferman, "Transmigration of eosinophils through basement membrane components in vitro: synergistic effects of plateletactivating factor and eosinophil-active cytokines," American Journal of Respiratory Cell and Molecular Biology, vol. 16, no. 4, pp. 455-463, 1997.

[3] P. J. Jose, D. A. Griffiths-Johnson, P. D. Collins et al., "Eotaxin: a potent eosinophil chemoattractant cytokine detected in a guinea pig model of allergic airways inflammation," Journal of Experimental Medicine, vol. 179, no. 3, pp. 881-887, 1994.

[4] S. J. Bensinger and P. Tontonoz, "Integration of metabolism and inflammation by lipid-activated nuclear receptors," Nature, vol. 454, no. 7203, pp. 470-477, 2008.

[5] I. Issemann and S. Green, "Activation of a member of the steroid hormone receptor superfamily by peroxisome proliferators," Nature, vol. 347, no. 6294, pp. 645-650, 1990.

[6] S. A. Kliewer, B. M. Forman, B. Blumberg et al., "Differential expression and activation of a family of murine peroxisome proliferator-activated receptors," Proceedings of the National Academy of Sciences of the United States of America, vol. 91, no. 15, pp. 7355-7359, 1994.

[7] L. Michalik, J. Auwerx, J. P. Berger et al., "International union of pharmacology. LXI. Peroxisome proliferator-activated receptors," Pharmacological Reviews, vol. 58, no. 4, pp. 726741, 2006.

[8] H. J. Patel, M. G. Belvisi, D. Bishop-Bailey, M. H. Yacoub, and J. A. Mitchell, "Activation of peroxisome proliferatoractivated receptors in human airway smooth muscle cells has a superior anti-inflammatory profile to corticosteroids: relevance for chronic obstructive pulmonary disease therapy," Journal of Immunology, vol. 170, no. 5, pp. 2663-2669, 2003.
[9] M. Spears, C. McSharry, and N. C. Thomson, "Peroxisome proliferator-activated receptor- $\gamma$ agonists as potential antiinflammatory agents in asthma and chronic obstructive pulmonary disease," Clinical and Experimental Allergy, vol. 36, no. 12, pp. 1494-1504, 2006.

[10] L. Benayoun, S. Letuve, A. Druilhe et al., "Regulation of peroxisome proliferator-activated receptor $\gamma$ expression in human asthmatic airways: relationship with proliferation, apoptosis, and airway remodeling," American Journal of Respiratory and Critical Care Medicine, vol. 164, no. 8, pp. 1487-1494, 2001.

[11] M. Kobayashi, M. J. Thomassen, T. Rambasek et al., "An inverse relationship between peroxisome proliferatoractivated receptor $\gamma$ and allergic airway inflammation in an allergen challenge model," Annals of Allergy, Asthma and Immunology, vol. 95, no. 5, pp. 468-473, 2005.

[12] R. K. So, S. L. Kyung, S. P. Hee et al., "Involvement of IL-10 in peroxisome proliferator-activated receptor $\gamma$-mediated antiinflammatory response in asthma," Molecular Pharmacology, vol. 68, no. 6, pp. 1568-1575, 2005.

[13] A. Trifilieff, A. Bench, M. Hanley, D. Bayley, E. Campbell, and P. Whittaker, "PPAR- $\alpha$ and $-\gamma$ but not $-\delta$ agonists inhibit airway inflammation in a murine model of asthma: in vitro evidence for an NF- $\kappa \mathrm{B}$-independent effect," British Journal of Pharmacology, vol. 139, no. 1, pp. 163-171, 2003.

[14] Y. Kobayashi, S. Ueki, G. Mahemuti et al., "Physiological levels of 15 -deoxy- $\Delta 12,14$-prostaglandin J2 prime eotaxininduced chemotaxis on human eosinophils through peroxisome proliferator-activated receptor- $\gamma$ ligation," Journal of Immunology, vol. 175, no. 9, pp. 5744-5750, 2005.

[15] S. H. Zigmond and J. G. Hirsch, "Leukocyte locomotion and chemotaxis. New methods for evaluation, and demonstration of a cell-derived chemotactic factor," Journal of Experimental Medicine, vol. 137, no. 2, pp. 387-410, 1973.

[16] R. Sehmi, A. J. Wardlaw, O. Cromwell, K. Kurihara, P. Waltmann, and A. B. Kay, "Interleukin-5 selectively enhances the chemotactic response of eosinophils obtained from normal but not eosinophilic subjects," Blood, vol. 79, no. 11, pp. 29522959, 1992.

[17] A. M. Thurau, U. Schulz, V. Wolf, N. Krug, and U. Schauer, "Identification of eosinophils by flow cytometry," Cytometry, vol. 23, no. 2, pp. 150-158, 1996.

[18] L. J. Janssen, L. Farkas, T. Rahman, and M. R. J. Kolb, "ATP stimulates $\mathrm{Ca}^{2+}$-waves and gene expression in cultured human pulmonary fibroblasts," International Journal of Biochemistry and Cell Biology, vol. 41, no. 12, pp. 2477-2484, 2009.

[19] P. Friedl and B. Weigelin, "Interstitial leukocyte migration and immune function," Nature Immunology, vol. 9, no. 9, pp. 960969, 2008.

[20] G. A. Dunn, "Characterising a kinesis response: time averaged measures of cell speed and directional persistence," Agents and Actions Supplements, vol. 12, pp. 14-33, 1983.

[21] J. M. Lehmann, L. B. Moore, T. A. Smith-Oliver, W. O. Wilkison, T. M. Willson, and S. A. Kliewer, "An antidiabetic thiazolidinedione is a high affinity ligand for peroxisome proliferator-activated receptor $\gamma(\operatorname{PPAR} \gamma)$," The Journal of Biological Chemistry, vol. 270, no. 22, pp. 12953-12956, 1995.

[22] P. J. Brown, D. A. Winegar, K. D. Plunket et al., "A ureidothioisobutyric acid (GW9578) is a subtype-selective PPAR $\alpha$ agonist with potent lipid-lowering activity," Journal of Medicinal Chemistry, vol. 42, no. 19, pp. 3785-3788, 1999.

[23] W. R. Oliver, J. L. Shenk, M. R. Snaith et al., "A selective peroxisome proliferator-activated receptor $\delta$ agonist promotes 
reverse cholesterol transport," Proceedings of the National Academy of Sciences of the United States of America, vol. 98, no. 9, pp. 5306-5311, 2001.

[24] P. W. Young, D. R. Buckle, B. C. C. Cantello et al., "Identification of high-affinity binding sites for the insulin sensitizer rosiglitazone (BRL-49653) in rodent and human adipocytes using a radioiodinated ligand for peroxisomal proliferatoractivated receptor $\gamma$," Journal of Pharmacology and Experimental Therapeutics, vol. 284, no. 2, pp. 751-759, 1998. 


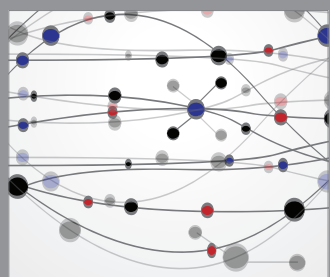

The Scientific World Journal
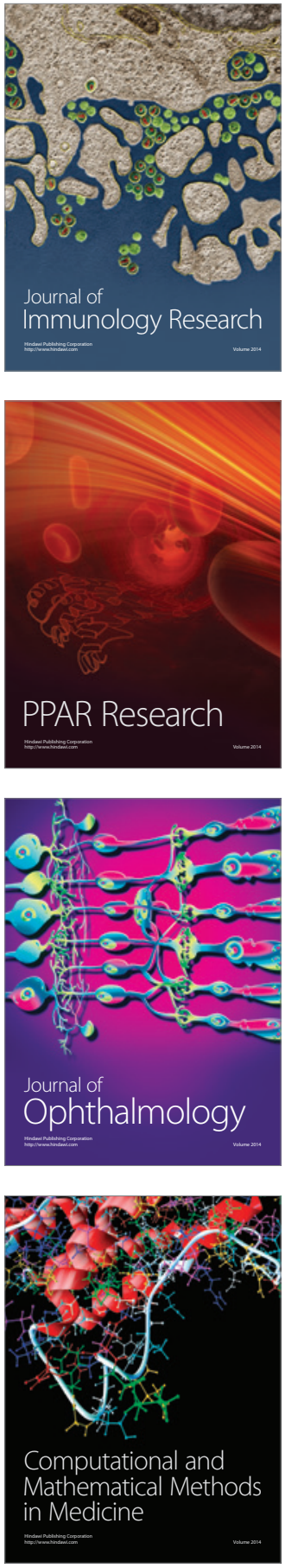

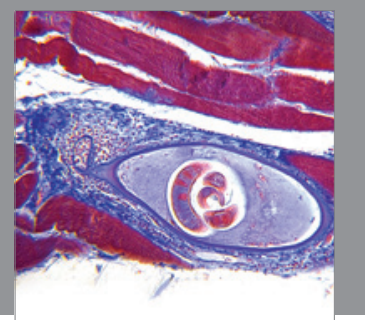

Gastroenterology

Research and Practice
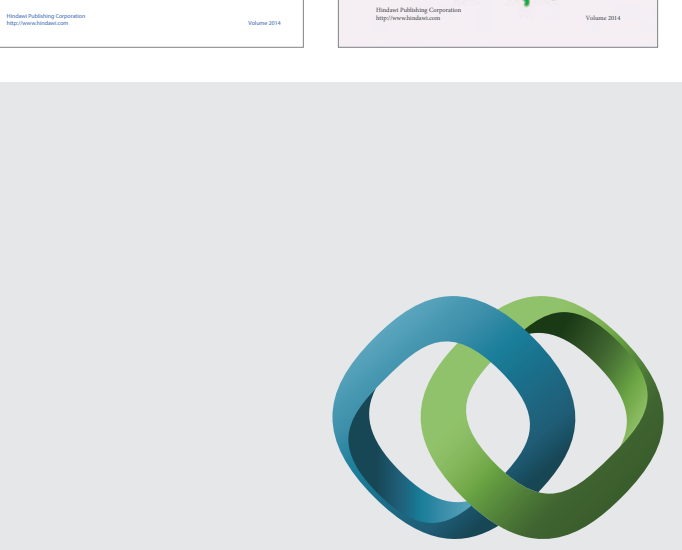

\section{Hindawi}

Submit your manuscripts at

http://www.hindawi.com
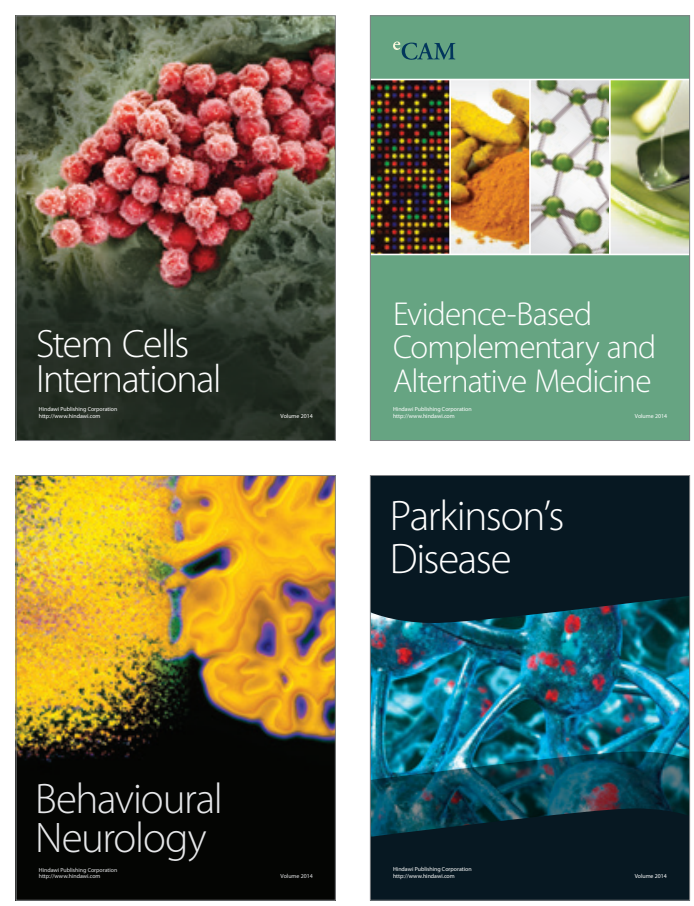

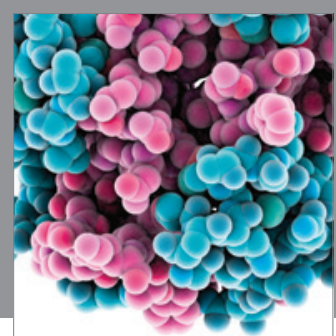

Journal of
Diabetes Research

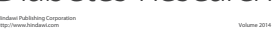

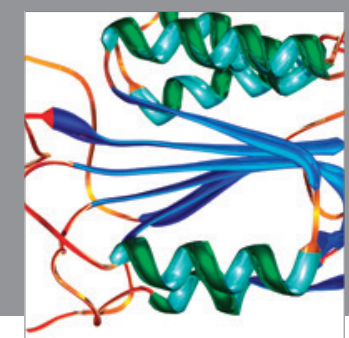

Disease Markers
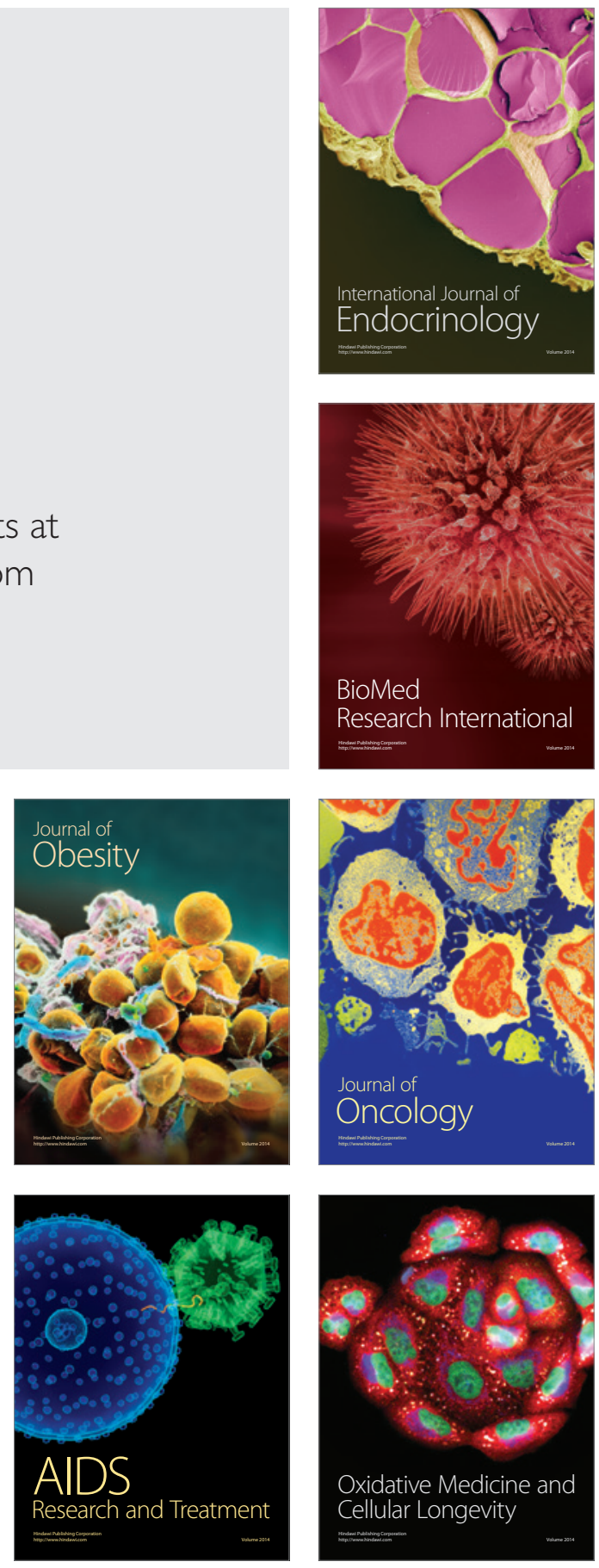